\title{
Assessment of quality of life in a retrospective study of total oral rehabilitation of the upper jaw with transzygomatic fixation - Case series
}

\section{Pinheiro $L^{1}$, Duarte $F^{2}$, Severino $E^{3}$, Leeson $R^{4}$, Hopper $C^{5}$}

\section{Affiliations:}

1. Master of Science in Oral and Maxillofacial Surgery at Eastman Dental Institute - University College of London

CEO and Clinical Director of Cero - Lisbon

- Portugal

2. Oral Surgeon Specialist by OMD (Portuguese Dental Association)

Master of Science in Oral and Maxillofacial Surgery at Eastman Dental Institute - University College of London

Professor at ISAVE - Instituto Superior de Saúde - Portugal

CEO and Clinical Director of Clitrofa - Trofa - Portugal

3. Professor at Faculty of Sciences - University of Lisbon - Portugal

Department of Statistics and Operational Research

4.UCL Eastman Dental Institute

Oral \& Maxillofacial Surgery Department

5.UCL Eastman Dental Institute

Oral \& Maxillofacial Surgery Department

\section{Corresponding author:}

Luis Pinheiro

Cero CEO and Clinical Director of Cero - Lisbon

- Portugal

luis.pinheiro.16@ucl.ac.uk

\section{ABSTRACT}

Purpose: Zygomatic implants are becoming more common in oral rehabilitation of atrophic maxilla. Successful surgery and rehabilitation are mandatory for the achievement of a well-defined criteria of Quality of Life. However, there is a paucity of studies reporting on the Health-Related Quality of Life in patients undergoing oral rehabilitation.

This article aims to developing a specific questionnaire for this particular surgical and rehabilitation procedure that could be an objective quality outcome measure of Quality of Life. This should improve our understanding of the impact of zygomatic implant placement on Quality of Life.

Materials and Methods: The study was performed involving the Eastman Dental Institute - University College of London, the Faculty of Sciences - University of Lisbon, and two private practices in Portugal, C.E.R.O-Lisboa and Clitrofa. This was a retrospective study, evolving 30 patients undergoing transzygomatic surgery.

A modification of the University of Washington - Quality of Life Questionnaire was designed for this work. The evaluation was made in three-time points: TP1 - Before surgery, TP2 - After surgery and TP3 - After final rehabilitation.

Results: The means of the increased Quality of Life between the different time-points were found to be statistically significance at the level of 0.05 , with a confidence interval of $95 \%$.

Conclusion: With this Questionnaire, important data was collected which should allow treatment developments to optimise patients Quality of Life.

\section{KEYWORDS}

Quality of life, maxillary atrophy, zygomatic implants 


\section{INTRODUCTION}

There are relations between different concepts, like Health, Quality of Life and Well-Being and Health-Related Quality of Life. ${ }^{13}$ The scientific community must know if the treatments that are being offered to the patients are making a positive, visible changing and improving or recovering their Quality of Life. The way a person selects their food is not necessarily a straightforward process and may be affected by ability to bite and chew. ${ }^{4}$ Softer and more easily chewed food is preferred, which is lower in fibre and less nutrient dense.,17 The state of dentition affects what people select to eat and this may affect their nutritional state and well-being. ${ }^{22}$ People who cannot chew and bite comfortably appear to have more risks of nutritional and gastrointestinal disorders. ${ }^{3}$

Complete dentures require retention, stability, aesthetics, phonetics, and comfort, which can lead to healthy supporting tissues and make it possible to achieve satisfaction. ${ }^{18}$

Implant-supported prosthesis have a more positive effect on patients' well-being than denture replacements. ${ }^{14}$ Fixed prosthesis functioned physically as their own teeth and most informants said that they had regained the self-esteem they once had and that their psychological, physical and social well-being was considerably improved..$^{25}$ Dental implantology is evolving rapidly, but there is, on the other hand, continuous pressure to place implants in sites that were once considered to have insufficient bone. ${ }^{10}$

\section{QUALITY OF LIFE ASSESSMENT}

The objective of oral rehabilitation is to restore function and thus promote patient well-being. ${ }^{21}$ Endosteal implants are often required..$^{12}$ There is a paucity of studies reporting on the HealthRelated Quality of Life (HRQOL) in patients undergoing oral rehabilitation. ${ }^{23}$

There are no questionnaires that focus on the various aspects of oral function in detail. ${ }^{19}$ Conventional head and neck questionnaires are not specifics and sensitive enough to access the success or failure of rehabilitation or oral function as the number of items pertaining to issues such as chewing is limited. ${ }^{19}$ The development of specific questionnaires is becoming more prevalent as familiarity with HRQOL enquiry and limitations of the broad head and neck questionnaires have been started to be appreciated, e.g. shoulder 24 and dysphagia. ${ }^{6}$ The view of some researchers is that finding a test that meets all of these criteria is as difficult as finding the Holy Grail.

The UW-QOL has been used widely since 1993, to assess HR-QOL in various clinical settings. ${ }^{15}$

The Quality of Life Assessment is an updated and extremely relevant issue and scientific and medical community should be able to work on different kind of instruments to assess patients before, during and after the treatments.

\section{PATIENT SELECTION}

The treatment is prescribed based on the availability of bone in maxillary zones. Zone I is the premaxilla, Zone II is the bicuspid zone (premolar), and Zone III is the posterior maxilla. ${ }^{1}$

An anterior tilted implant concept is considered in patients with bone in both Zones I and II. The zygomatic implant concept is considered in patients who demonstrate bone in Zone I only. ${ }^{1}$

The main advantage in providing the edentulous patient with a stable, fixed, provisional prosthesis is an immediate improvement in the patient's ability to function with a positive boost of their self-esteem and these factors together allow for a higher treatment acceptance. ${ }^{2}$ With the trend of shortening treatment time and reducing patient discomfort, immediate

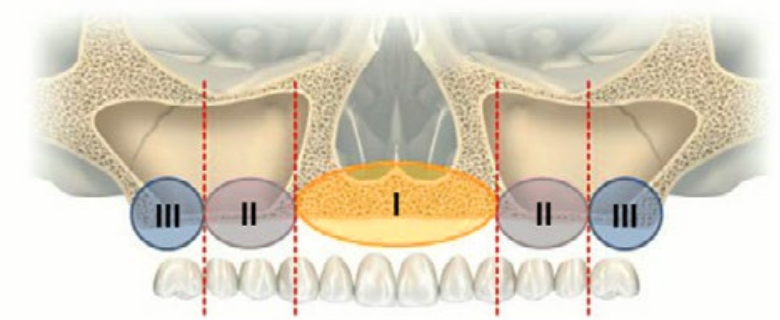

Figure 1. Zones of the maxilla; presence or absence of the zones dictates the surgical concept

\begin{tabular}{ll}
\hline Presence of bone & Surgical approach \\
\hline Zones I, II and III & Traditional (axial) implants \\
\hline Zones I and II & Folur traditional implants (tilted) \\
\hline Zone I only & $\begin{array}{c}\text { Zygomatic implants plus } \\
\text { two or four traditional implants }\end{array}$ \\
\hline Insufficient bone & Four zygomatic implants \\
\hline
\end{tabular}

Table 1. Treatment recommendations based on the presence of bone in the different zones of the maxilla

loading implants has emerged. ${ }^{11}$

With all these advantages, there is an increase in the patient's Quality of Life. The concept of immediate function includes immediate aesthetics and immediate occlusal loading.? Immediate loading has achieved similar success rated when compared to other loading protocols. . $^{8,1,20}$

\section{MATERIALS AND METHODS}

\section{Study Design}

The study was performed involving Eastman Dental Institute University College of London, the Faculty of Sciences - University of Lisbon, and two private practices in Portugal, C.E.R.O-Lisboa and Clitrofa. This was a retrospective study, evolving 30 patients undergoing transzygomatic surgery. The patients had only zygomatic implants or zygomatic implants combined with standard implants.

\section{Inclusion Criteria}

- ASA I and ASA II Patients classified by our Anaesthetist Team.

- Patient must have at least one zygomatic implant placed during the surgery.

- Lower jaw with complete rehabilitation, after appointment with our Oral Rehabilitation Team.

- Balanced Occlusion between both jaws after our oral rehabilitation.

- Diabetic and Hypertensive conditions under control with medication and the overview of the general practitioner or the proper specialist.

- The patient must return to control and maintenance appointments after the surgery, during the provisional rehabilitation, and after the final rehabilitation.

- Only patients with no prosthesis failed or no implant failed were included in this study.

\section{Follow-up Protocol}

- These implants were considered to be successful if they were asymptomatic without any sign of infection and stable without mobility. ${ }^{7}$ A successful implant was a stable implant 
as confirmed by tightening the screws of the abutment at 20 $\mathrm{N} / \mathrm{cm} 2$ torque. ${ }^{9}$ A failed implant was an implant that presented rotational mobility, had to be removed or was fractured and a slight bending movement in zygomatic implant was accepted and considered normal. ${ }^{9}$ Lack of gross mobility as well absence of pain upon percussion along with no sigh of periimplant pathology were also survival criteria. ${ }^{2}$

- All the patients had to come to follow up after surgery after 10 to 12 days.

- All the patients with immediate loading had to come every month to follow up until they had the final rehabilitation.

- All the patients without immediate loading had to come every month to follow up to access the provisional removable prosthesis and replace the tissue conditioner.

- All patients had to come to follow up every 6 months after the final oral rehabilitation.

- Orthopantomography before surgery, after surgery and after final rehabilitation.

- Cone Bean Computed Tomography had to be made at least before the surgery to be included in the surgical study and planning of the case.

\section{Exclusion Criteria}

- Heavy Smokers, more than 10 cigarettes a day.

- Insufficient Oral Hygiene, after the Oral Hygiene appointment and re-assessment after two weeks.

- Untreated Depression and uncontrolled anxiety.

- Psychiatric condition.

- Untreated sinus infection or not controlled chronic sinusitis.

- Absolute contra-indications for implant surgery.

\section{Surgical Protocol}

The surgeries in all the 30 patients were performed under general anaesthesia by two surgeons working together with their teams. The surgeries range from 2002 to 2017. The total number of implants placed was:

- Zygomatic Implants - (n=69) with the Cumulative Survival Rate (C.S.R.) of $100 \%$

- Conventional Implants - $(\mathrm{n}=90)$ with the Cumulative Survival Rate (C.S.R.) of $100 \%$

\section{Prosthetic Protocol}

The oral prosthetic rehabilitation was performed by the departments of oral rehabilitation of each private practice in their own dental laboratories which made all the quality assessment of the prosthesis more predictable and accurate.

\section{Quality of Life Assessment}

A revision about the use of questionnaires in oral rehabilitation and in oral and maxillofacial surgery has been done. A modification to the University of Washington - Quality of Life Questionnaire was made in this work, because there was no questionnaire that had all the criteria for this present study, like specificity and validity to the items and kind of surgery/ rehabilitation performed. ${ }^{26}$

A retrospective study was designed, based on the justification that when patients were submitted to the surgeries and after rehabilitations there was not, yet this version made of the "UW - QoL" questionnaire. At the moment of the questionnaire fulfilment, the patients were helped to answer based on their own memories of a lived experience and with clinical files, clinical records, clinical photographs and radiological exams.

\section{Ethics}

The study was conducted in agreement with the ethical considerations of the Portuguese Data Protection Authority (CNPD) and the entire content of the decision issued under no. 2605/2018 on 05-03-2018.

\section{Materials and Methods}

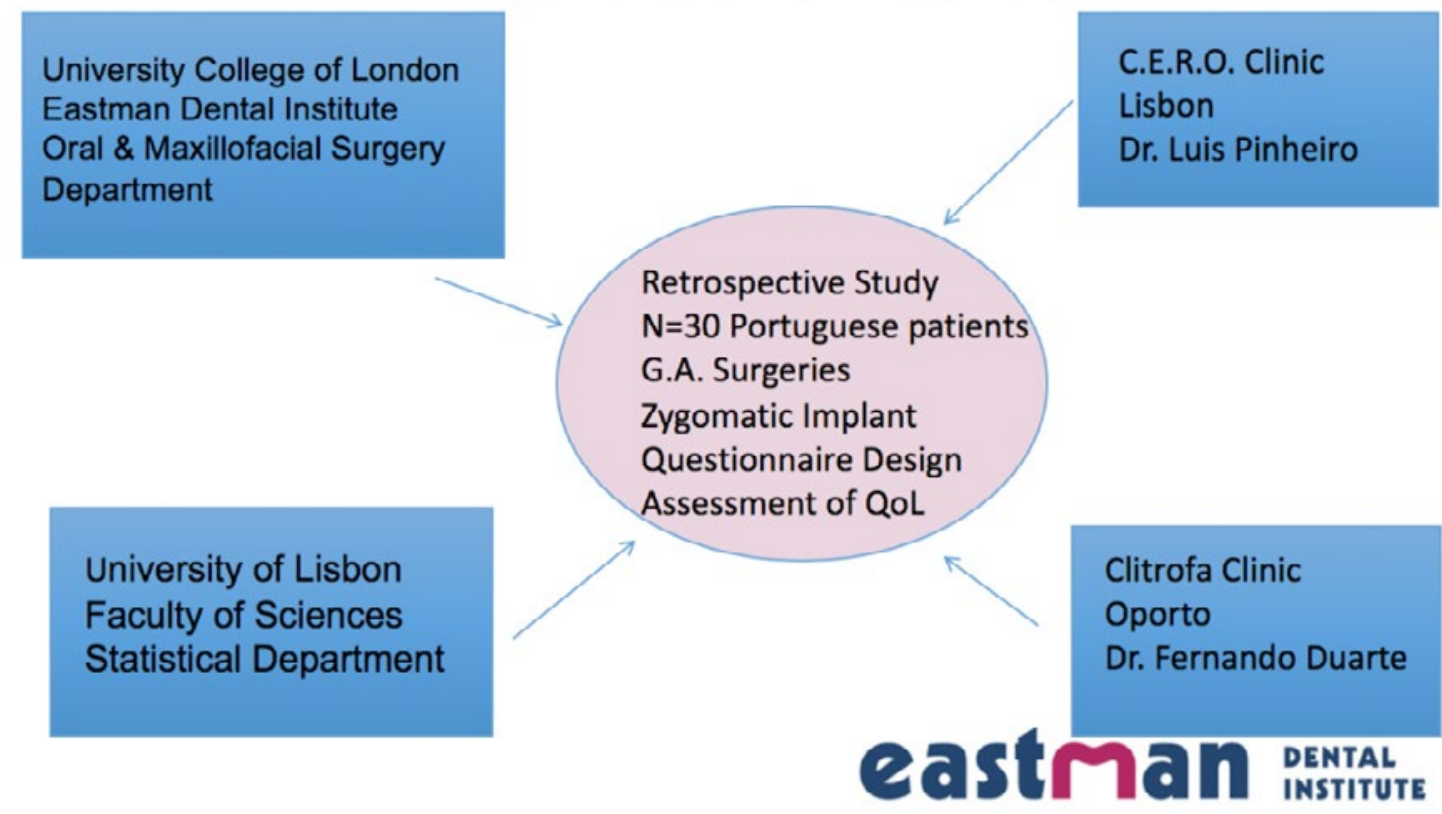

Figure 2. Study design 


\section{RESULTS}

All patients had to read the "Patient Information Sheet" document and had to sign the "Informed Consent Form" document before answer the Questionnaire. Patients had answered the "Informed Consent Form" document before answer the Questionnaire. Patients had answered the "University College of London, Eastman Dental Institute - Quality of Life Questionnaire for patients subject to total oral rehabilitation of the upper jaw with transzygomatic fixation" (UCL-QoL-TOL-TzyFx) in an interview with the principal investigator of this project.

As recommended, quality of life instruments should be administered a minimum of three times, with timing dependent on disease and treatment parameters, typically at baseline, during therapy at time when maximal assessment of side effects is possible and at the end of the treatment. ${ }^{16}$

There were determined three-time points to fulfil the questionnaire: Time Point 1 (TP1) - before treatment, Time Point 2 (TP2) - after transzygomatic surgery and Time Point 3 (TP3) after final oral rehabilitation.

Some of the patients after the surgery (TP2) had provisional immediate loading prosthesis and others had only fixed prosthetics structures after the healing process of osseointegration, after 6 waiting months. Healing for integration usually requires 5 to 6 months before impressions and subsequent prosthetic construction can be initiated (Parel SM, 2001). With this information, between TP2 and TP3, two different groups were also assessed: Group 1 - Temporary fixed structure with immediate loading implants (TFSwILI) and Group 2 - Others (where immediate loading was not possible).

\section{Patient demography}

Previous treatment or previous clinical condition that raised the need for the treatment: 1) Removable upper prosthesis with poor retention or stability, 2) Failure in the rehabilitation of cases treated with conventional implants, 3) Failure in the regeneration with bone graft and implants, 4) Bone and/or maxillary sinus infection, 5) Post-cancer surgery, 6) Failure in zygomatic implants, 7) Periodontal disease and 8) Major loss of teeth and/or destruction due to caries.

\section{Statistical Significance}

A good statistical significance was obtained in the assessment of the quality of life for this type of surgery and rehabilitation. Small sample size limited the power of the tests. This study's sample was $n=30$ in next studies, a powerful sample should be achieved. transzygomatic fixation, it's a major surgical procedure, and it's not so common as conventional dental implant surgeries. Other clinical centres could be also involved to achieve a larger sample and that's the reason to keep type 5 and type 7 indications even with zero results for this present project, for the simple reason that there are specialize centres for those 2 types.

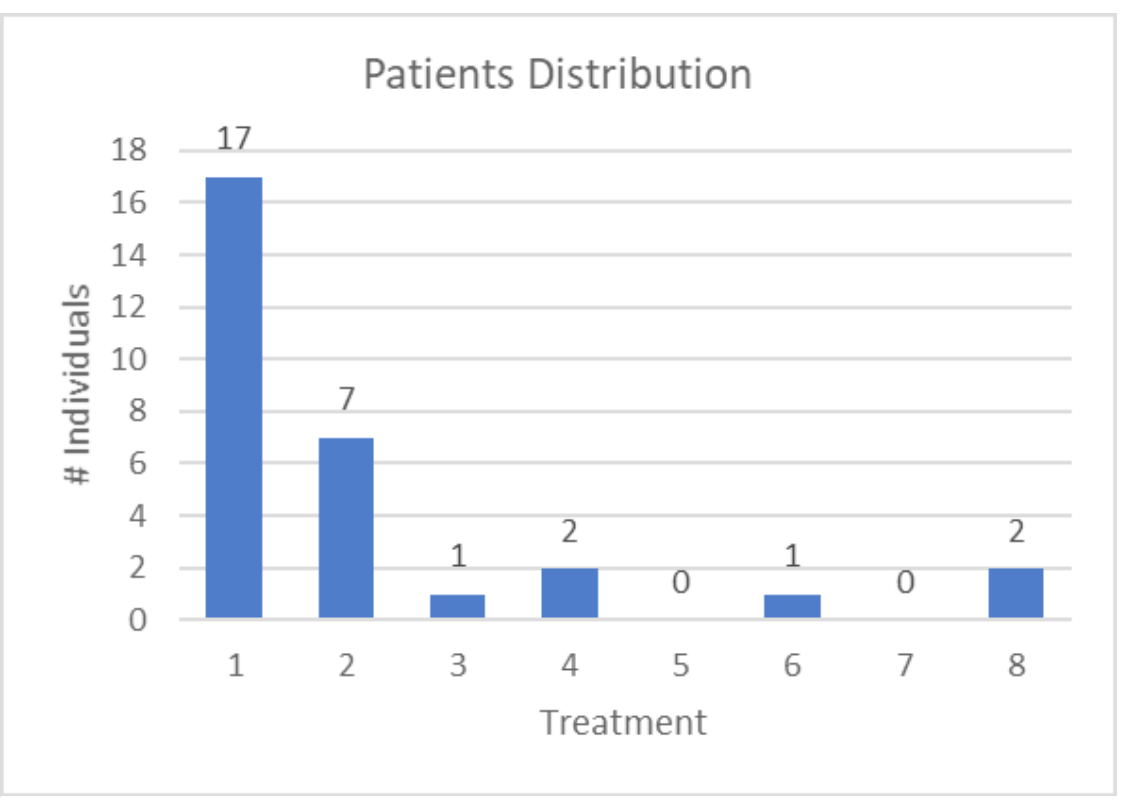

Figure 3. Patients distribution 


\section{Questionnaire Internal Consistency}

The Questionnaire has a Good Internal Consistency, which was already expected since the current questionnaire is a slight modification of the original questionnaire which Cronbach's alpha is 0.81 . The loss of any single item does not change the alpha coefficient to any great extent.

\begin{tabular}{|c|c|c|}
\hline \multicolumn{3}{|c|}{ Reliability Statistics } \\
\hline $\begin{array}{l}\text { Cronbach's } \\
\text { Alpha }\end{array}$ & $\begin{array}{c}\text { Cronbach's } \\
\text { Alpha Based } \\
\text { on } \\
\text { Standardized } \\
\text { Items }\end{array}$ & $\mathrm{N}$ of Items \\
\hline .80 & .81 & 12 \\
\hline
\end{tabular}

Table 1. Calculation of Cronbach's Alpha

\section{Item-Total Statistics}

\begin{tabular}{l|r|r|r|r|r} 
& $\begin{array}{c}\text { Scale Mean if } \\
\text { Item Deleted }\end{array}$ & $\begin{array}{c}\text { Scale } \\
\text { Variance if } \\
\text { Item Deleted }\end{array}$ & $\begin{array}{c}\text { Corrected } \\
\text { Item-Total } \\
\text { Correlation }\end{array}$ & $\begin{array}{c}\text { Squared } \\
\text { Multiple } \\
\text { Correlation }\end{array}$ & $\begin{array}{c}\text { Cronbach's } \\
\text { Alpha if Item } \\
\text { Deleted }\end{array}$ \\
\hline Pain_TP1 & 23.47 & 32.464 & .651 & .615 & .756 \\
\hline Appearance_TP1 & 22.90 & 41.541 & .173 & .394 & .807 \\
\hline Activity_TP1 & 24.37 & 37.826 & .671 & .652 & .766 \\
\hline Recreation_TP1 & 23.73 & 35.651 & .690 & .722 & .757 \\
\hline Swallowing_TP1 & 23.87 & 38.533 & .528 & .768 & .775 \\
\hline Chewing_TP1 & 23.53 & 41.292 & .372 & .663 & .789 \\
\hline Speech_TP1 & 24.07 & 37.651 & .693 & .657 & .764 \\
\hline OralHygiene_TP1 & 23.97 & 43.620 & .009 & .689 & .822 \\
\hline Taste_TP1 & 23.30 & 41.045 & .258 & .307 & .797 \\
\hline Saliva_TP1 & 24.57 & 42.047 & .323 & .304 & .792 \\
\hline Mood_TP1 & 23.50 & 34.879 & .732 & .768 & .752 \\
\hline Anxiety_TP1 & 22.90 & 33.886 & .462 & .597 & .788 \\
\hline
\end{tabular}

Table 2. Comparing different items correlations 


\section{Quality of Life Scores}

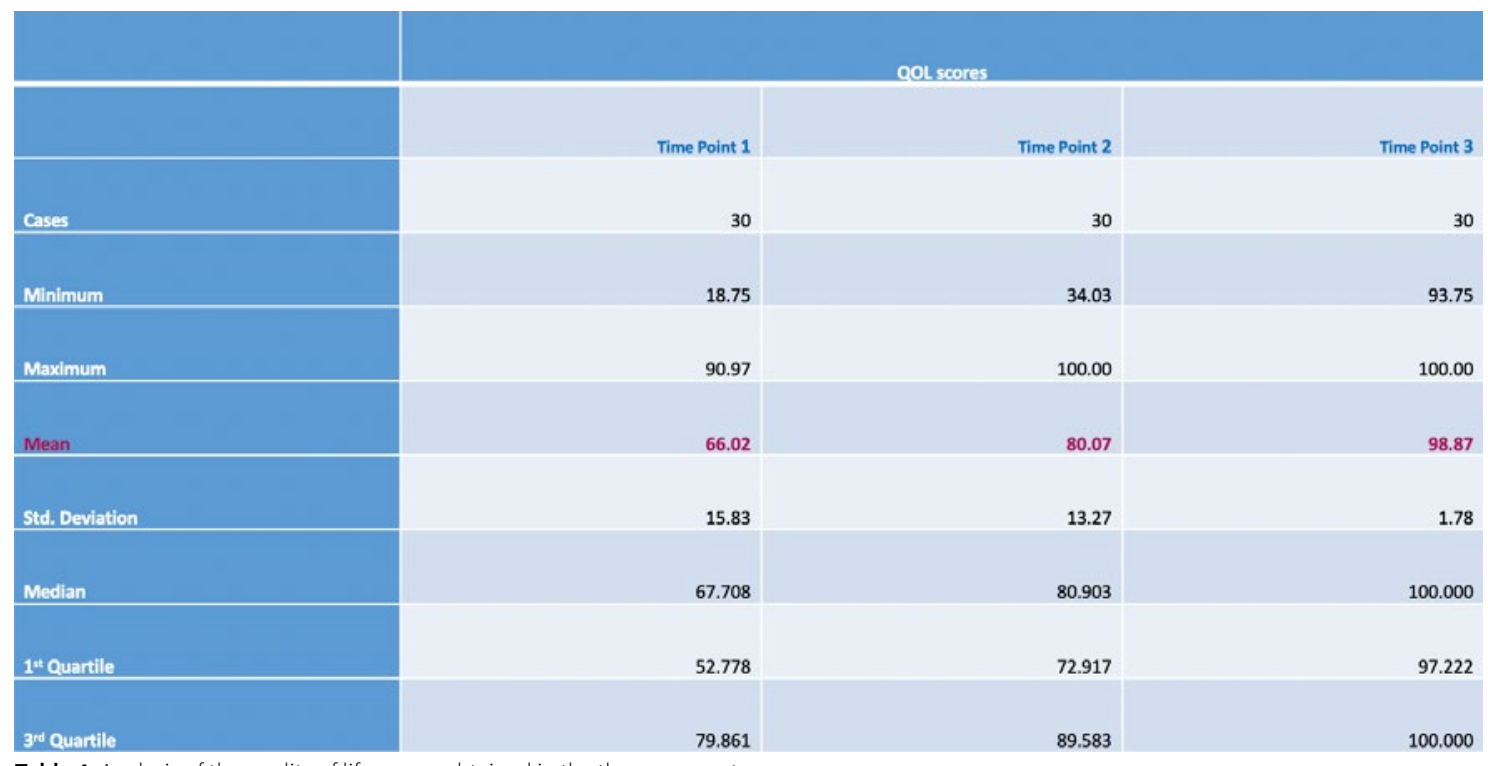

Table 4. Analysis of the quality of life scores obtained in the three moments

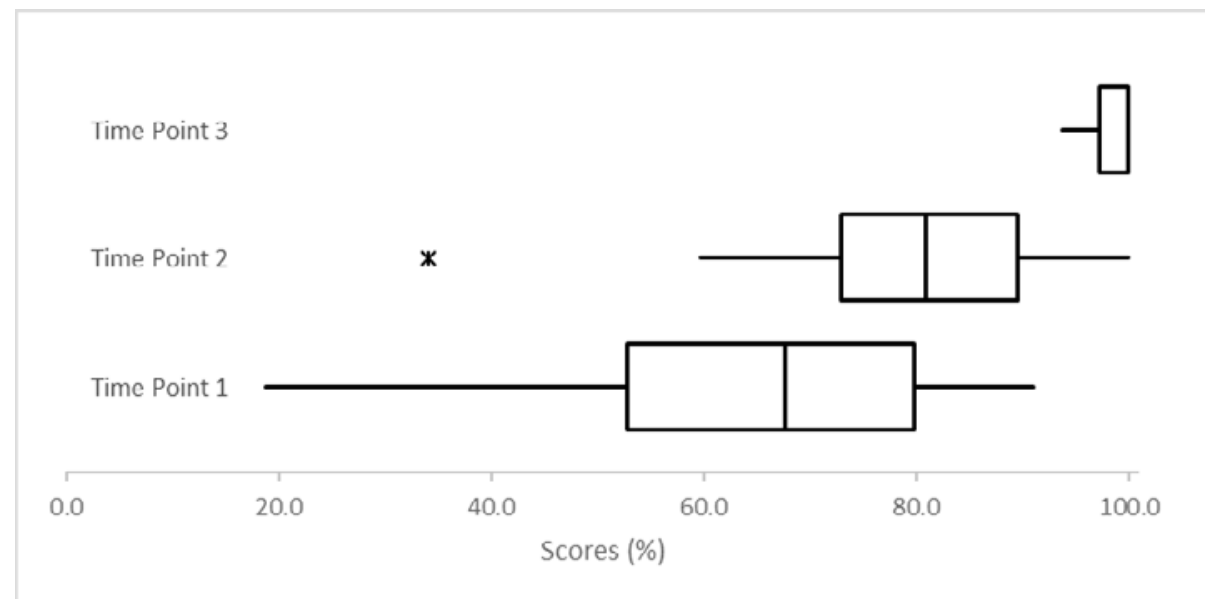

Figure 4. Quality of Life Scores distribution in the 3 different Time Points 
The outlier was our "Patient 22" that registered post-surgical pain and discomfort, with oedema, subsequent of pain and infection clinical manifestations on TP1, which caused and represented a decreased on "his/her" Quality of Live between TP1 and TP2.

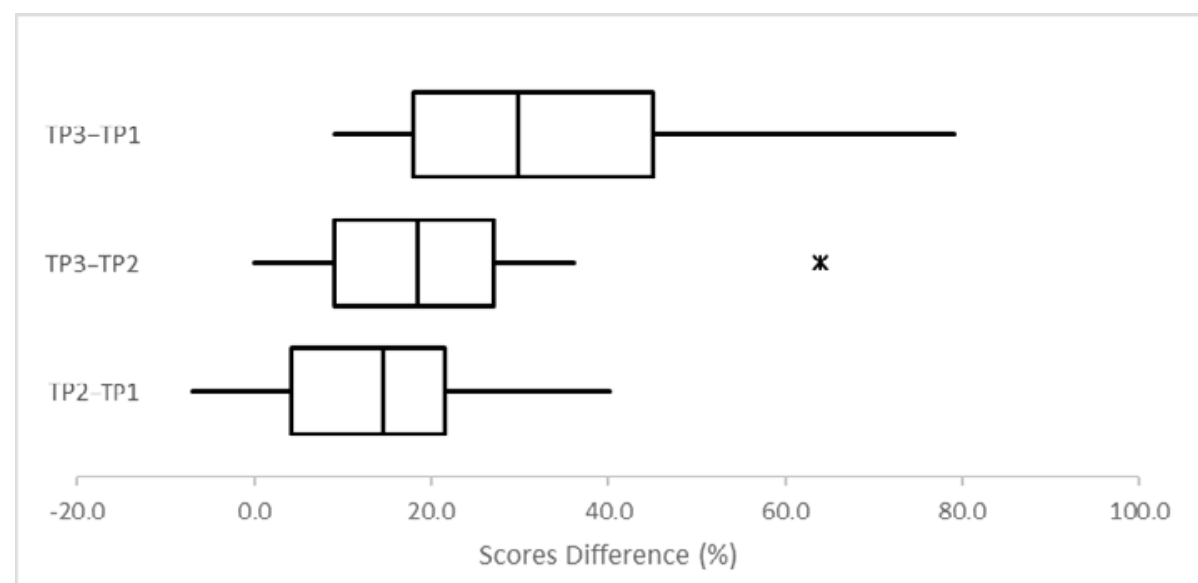

Figure 5. Quality of Life Scores distribution between 3 different Time Points

The same "Patient 22" revealed a great Quality of Live increasing from TP2 to TP3. Excluding the individual corresponding to outliers the skewness coefficients for Score TP2 - Score TP1, Score TP3 - Score TP1 and Score TP3 -Score TP2 turn out to be, respectively, equal to 0.278 (almost the same as previously),
0.027 (much smaller than previously), and -0.004 (almost equal to 0 ). Thus, it can be inferred that the new sample distributions are all symmetric, and repeating part of the analysis to check if the outlier corresponds also to an influential observation, we got:

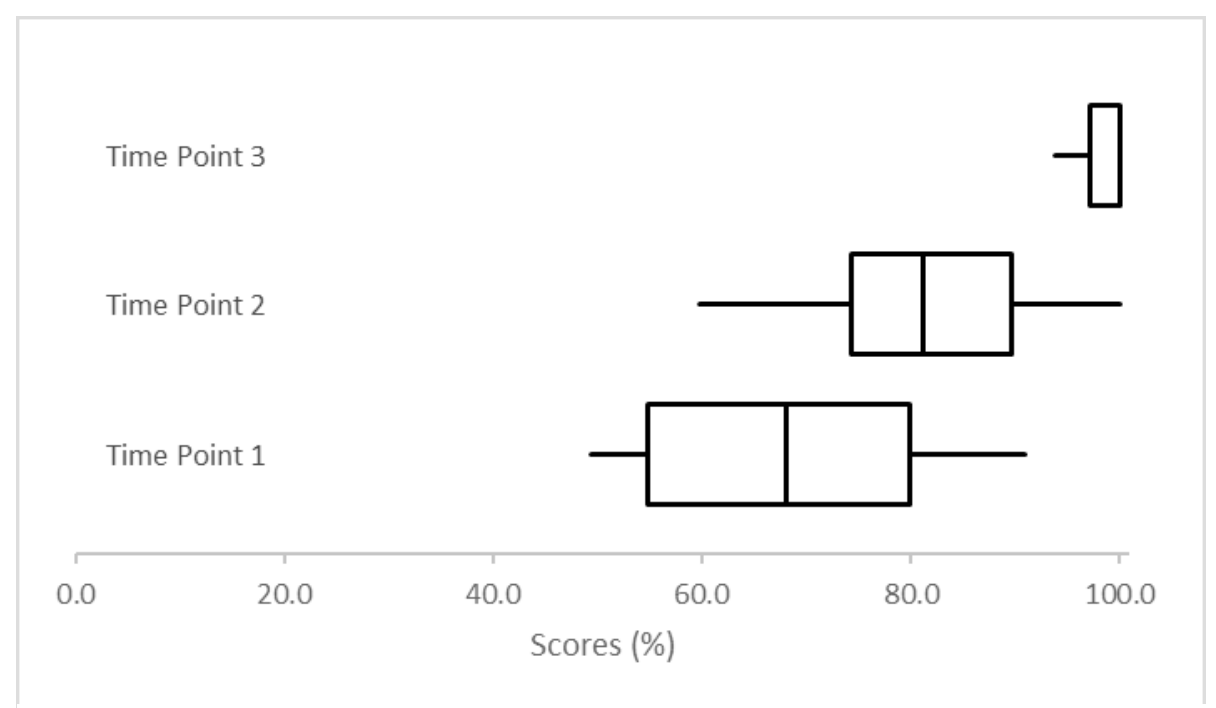

Figure 6. Quality of Life Scores distribution in the 3 different Time Points without the outlier

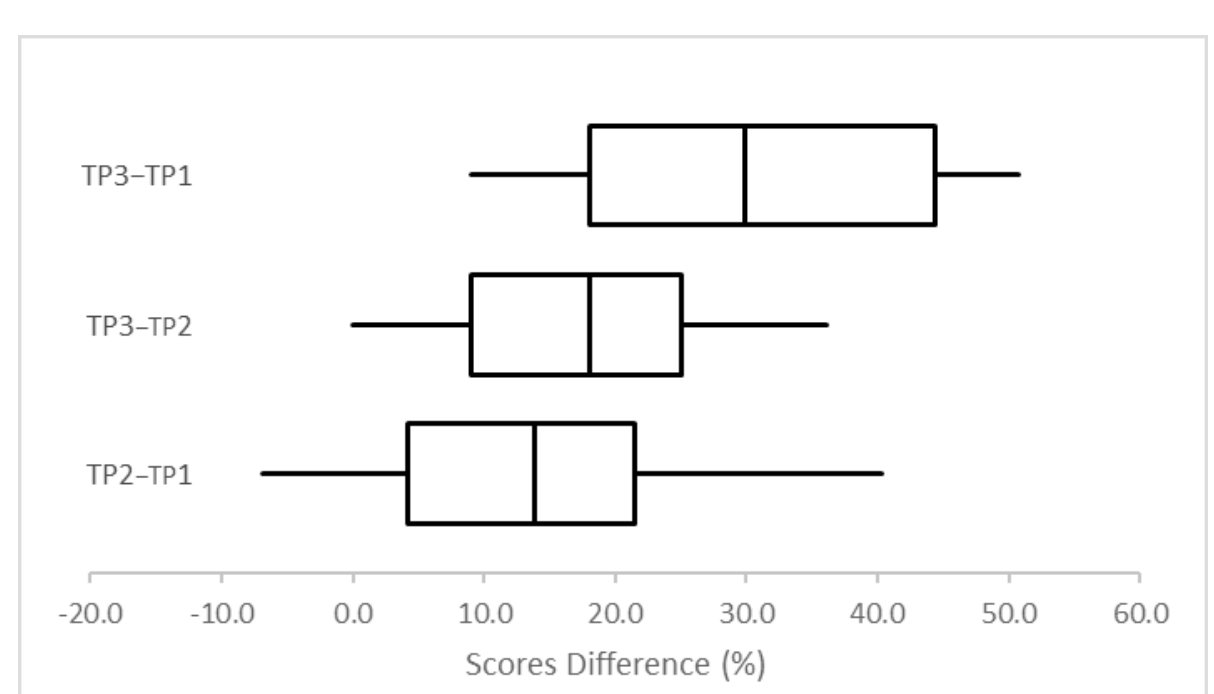

Figure 7. Quality of Life Scores difference in 3 different Time Points without the outlier 
Normality was tested between TP3 and TP2 without the outlier. Normality of Score TP3-Score TP2 is not rejected anymore (0.482
$>0.05)$. Using a T-test to compare the scores in those 2 Time Points yields:

\section{One-Sample Statistics}

\begin{tabular}{l|r|r|r|r} 
& N & Mean & Std. Deviation & \multicolumn{1}{c}{$\begin{array}{c}\text { Std. Error } \\
\text { Mean }\end{array}$} \\
\hline ScoreTP3_TP2_NoOut & 29 & 17.24069 & 10.210038 & 1.895957 \\
\hline
\end{tabular}

\begin{tabular}{|c|c|c|c|c|c|c|}
\hline \multicolumn{7}{|c|}{ One-Sample Test } \\
\hline & \multicolumn{6}{|c|}{ Test Value $=0$} \\
\hline & \multirow[b]{2}{*}{$t$} & \multirow[b]{2}{*}{ df } & \multirow[b]{2}{*}{ Sig. (2-tailed) } & \multirow{2}{*}{$\begin{array}{c}\text { Mean } \\
\text { Difference }\end{array}$} & \multicolumn{2}{|c|}{$\begin{array}{l}95 \% \text { Confidence Interval of the } \\
\text { Difference }\end{array}$} \\
\hline & & & & & Lower & Upper \\
\hline ScoreTP3_TP2_NoOut & 9.093 & 28 & .000 & 17.240690 & 13.35700 & 21.12438 \\
\hline
\end{tabular}

Table 5. Shows the use of Parametric Tests for testing Normality between TP3 and TP2 without the outlier.

Thus, the QOL in Time Point 3 is still significantly greater ( $p$-value $=0)$ than in Time Point 2 .

\section{Type of Temporary Rehabilitation}

Time Points 1 and 2 for comparison of difference of scores in groups according to the type of temporary rehabilitation: immediate vs delayed loading.

\section{Case Processing Summary}

\begin{tabular}{|c|c|c|c|c|c|c|c|}
\hline \multirow[b]{3}{*}{ Temp_Rehab } & & \multicolumn{6}{|c|}{ Cases } \\
\hline & & \multicolumn{2}{|c|}{ Valid } & \multicolumn{2}{|c|}{ Missing } & \multicolumn{2}{|c|}{ Total } \\
\hline & & N & Percent & N & Percent & N & Percent \\
\hline Others & Score_TP2-Score_TP1 & 18 & $100.0 \%$ & 0 & $0.0 \%$ & 18 & $100.0 \%$ \\
\hline $\begin{array}{l}\text { Temporary fred stucture } \\
\text { with immediately loaded } \\
\text { implants }\end{array}$ & Score_TP2-Score_TP1 & 12 & $100.0 \%$ & 0 & $0.0 \%$ & 12 & $100.0 \%$ \\
\hline
\end{tabular}

Table 6. Valid and missing patients inside both categories TFSwILI and Others between TP1 and TP2

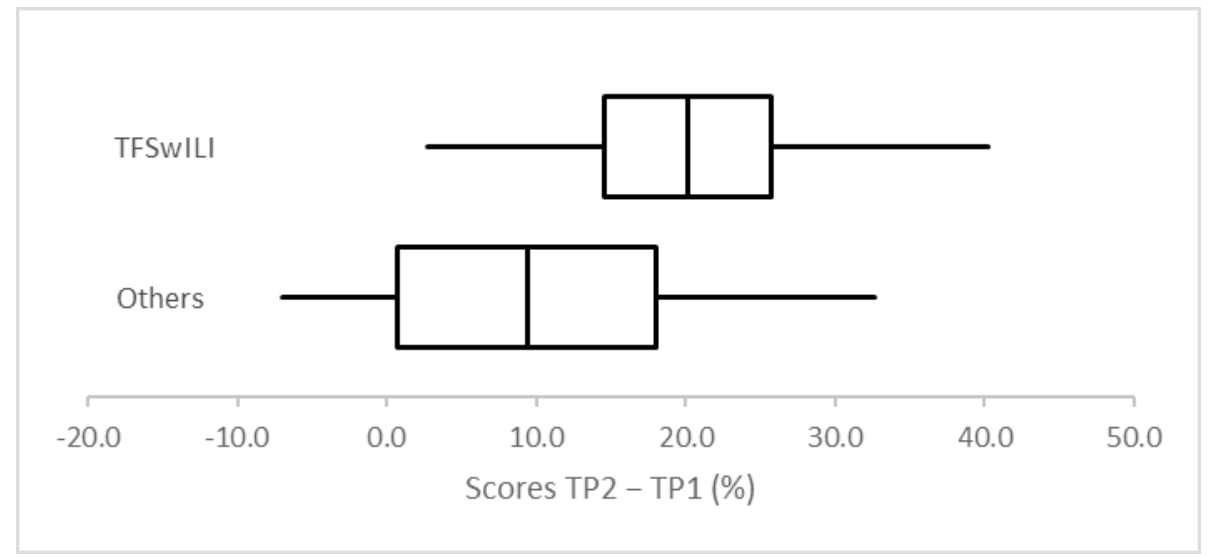

Figure 8. Temporary Fixed Structure with immediately loaded Implants vs Others 


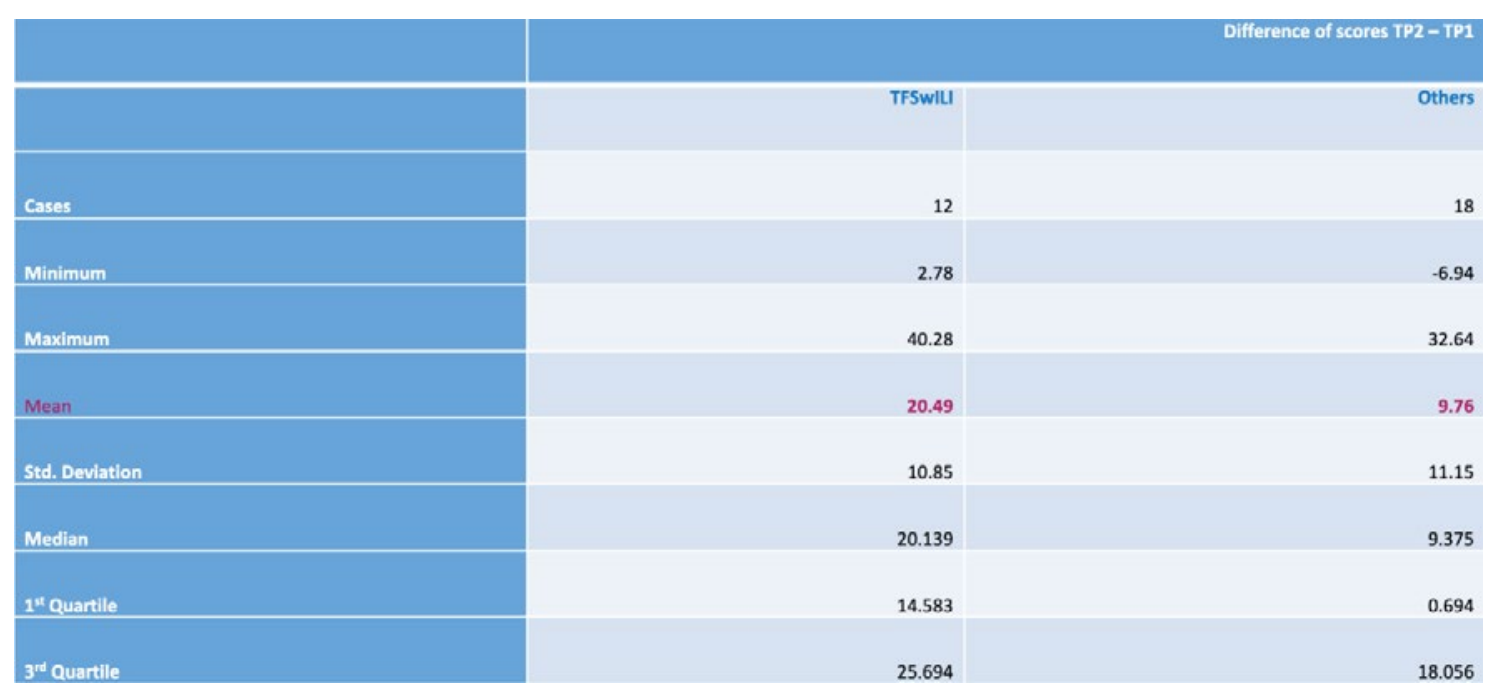

Table 7. Shows the difference of Temporary Fixed Structure with immediately loaded Implants (TFSwILI) vs Others scores between the TP2 and TP1.

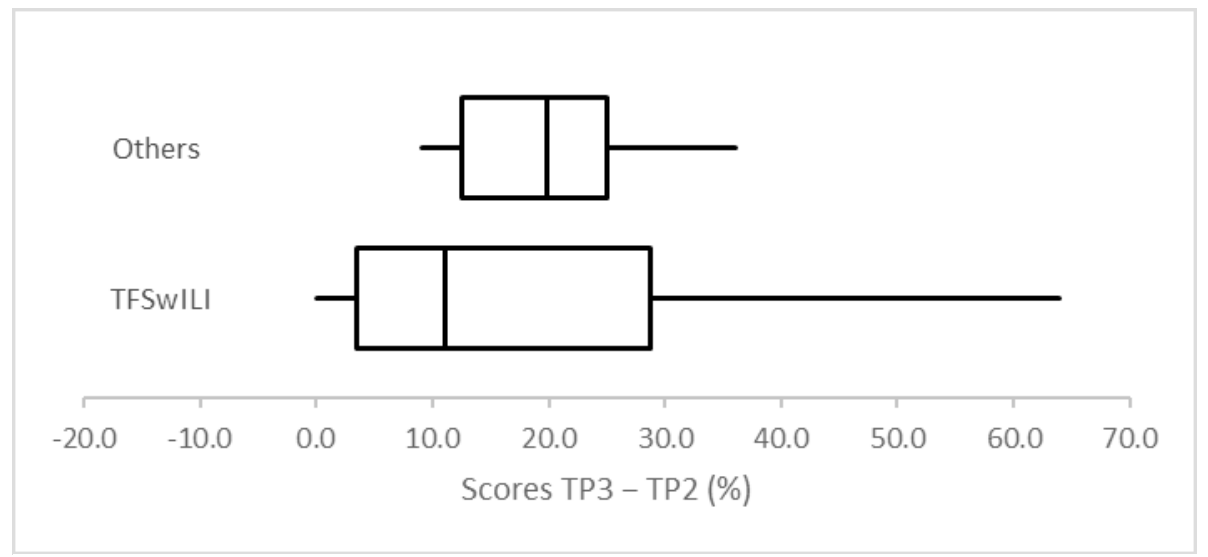

Figure 9. Shows the difference of scores between TP2 and TP3 in both Groups

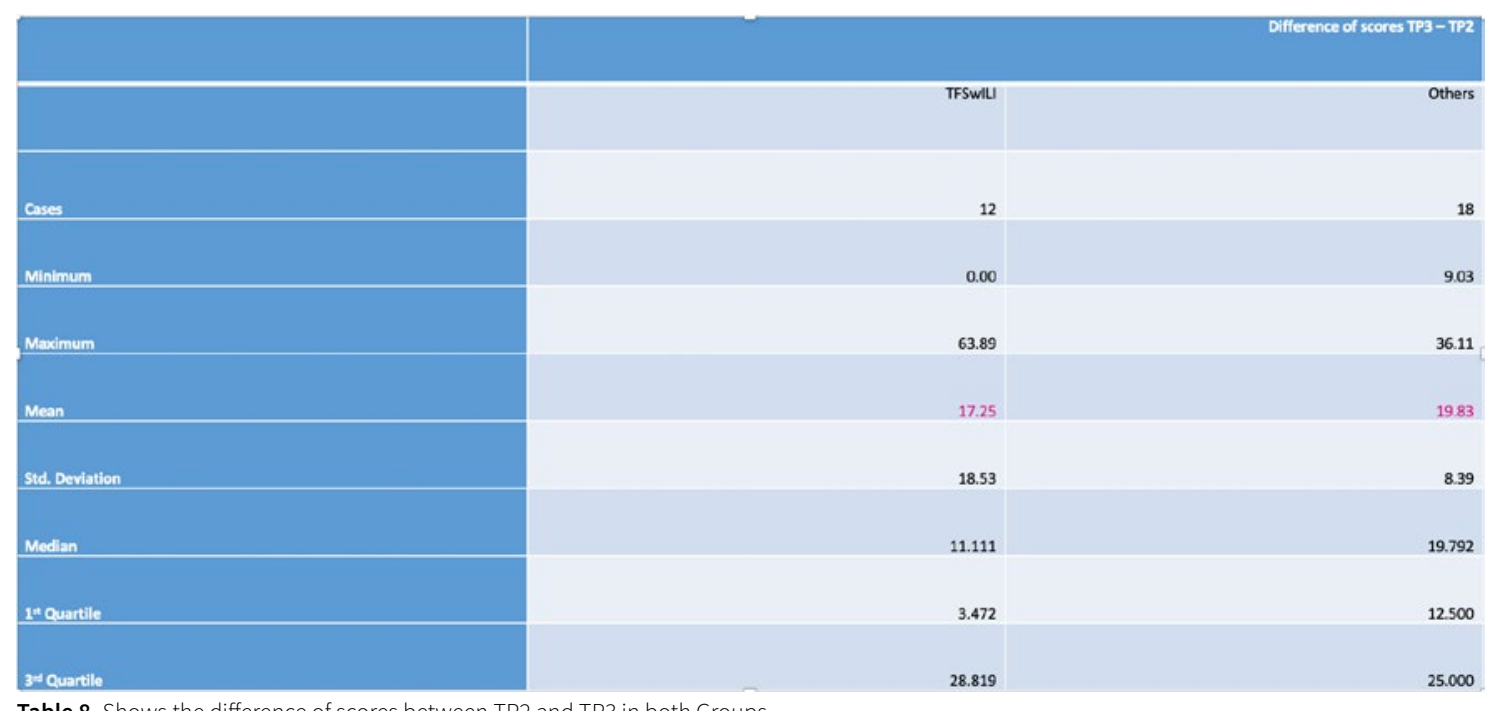

Table 8. Shows the difference of scores between TP2 and TP3 in both Groups 


\section{Expectations}

In the expectations evaluation twelve possibilities were

Swallowing, 6) Chewing, 7) Speech, 8) Oral Hygiene, 9) Taste, 10) considered: 1) Pain, 2) Appearance, 3) Activity, 4) Recreation, 5) Saliva, 11) Mood and 12) Anxiety.

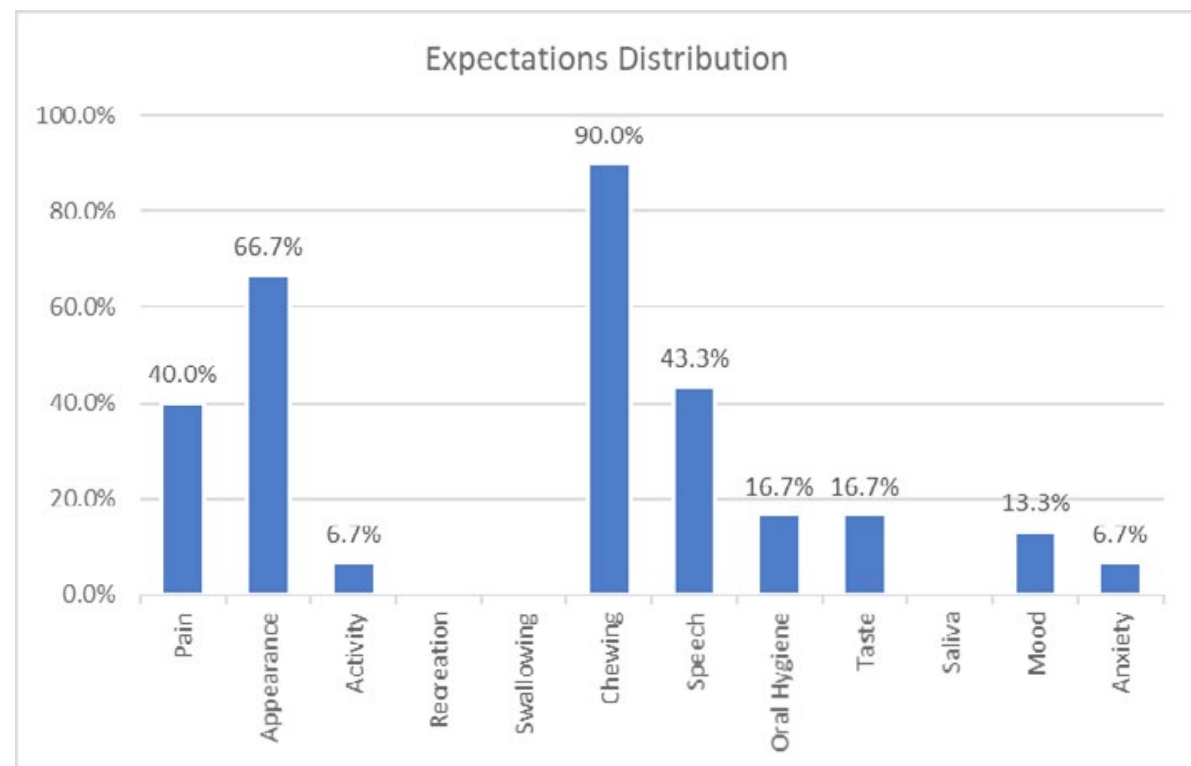

Figure10. Most important expectations selected by each patient

\section{Overall rating}

In the Overall rating five items of classification were considered: 1) Not achieved, 2) Some kind of achievement but not enough,
3) The expectation was achieved, but it could be better, 4) Expectation achieved with a good result and 5) Full expectation was achieved.

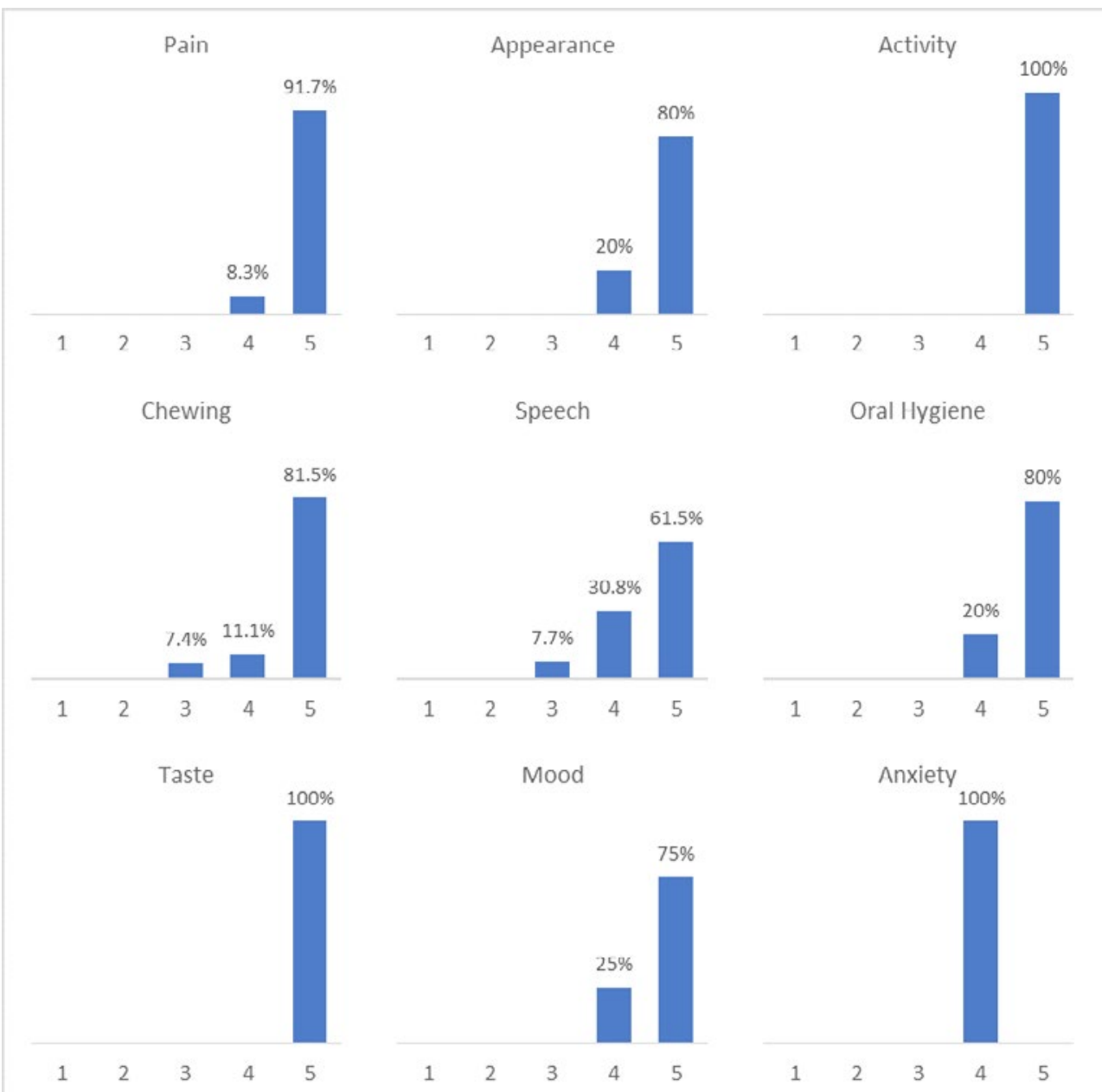

Figure11. Overall rating regarding the most important expectations 


\section{DISCUSSION}

With this first version of the " $U C L-Q o L-T O L-T Z y F x-V e r .1$ " it was pretended to create an outcome measure for quality of life assessment. It was clearly demonstrated with statistically significance that this treatment improved the quality of life of these 30 patients.

A questionnaire was validated with good internal consistency. Only patients with no failure of implants or prostheses were included in this study. The next version of the questionnaire should have a 4th Time Point for the immediate moment after the failure (prosthetic or surgical) and quality of life should be assessed on that moment, and data analysed in comparison with the others Time Points, previous and after.

Also, the second question of the questionnaire about the appearance must be reformulated in a way that an aesthetic improvement could be reported and not only decreasing appearance.

\section{CONCLUSION}

There are different implant techniques regarding to dental implant surgeries. Conventional and zygomatic, with different kind of protocols have been used in oral surgery and oral rehabilitation in order to achieve these main goals: a) No pain, b) No infection, c) Fixed prosthesis as soon as possible, d) Prosthesis easy to wear, e) Improved aesthetics, or at least no major appearance changes and f) A good rehabilitation that could make the patient eat and speak properly.

This project was about quality of life assessment and its relationship with patients' condition or disease, their physical, emotional, personal, professional and familiar aspects. A measure started to be design in a way that could count with all these different variables in patients that were submitted to transzygomatic implants surgery, to achieve a total oral fixed rehabilitation of the upper jaw.

With this project useful data was collected to improve and develop the treatment quality and ultimately, it will be patients who will benefit most from this approach.

\section{CONFLICT OF INTEREST}

The authors declared that there is no conflict of interest.

\section{REFERENCES}

1. Bedrossian E. Rescue implant concept: the expanded use of the zygoma implant in the graftless solutions. Dent Clin North Am. 2011 Oct;55(4):745-77.

2. Bedrossian E, Rangert B, Stumpel L, Indresano T. Immediate function with the zygomatic implant: a graftless solution for the patient with mild to advanced atrophy of the maxilla. Int J Oral Maxillofac Implants. 2006 Nov-Dec;21(6):937-42.

3. Brodeur JM, Laurin D, Vallee R, Lachapelle D. Nutrient intake and gastrointestinal disorders related to masticatory performance in the edentulous elderly. J Prosthet Dent. 1993 Nov;70(5):468-73.

4. Carlos JP, Wolfe MD. Methodological and nutritional issues in assessing the oral health of aged subjects. Am J Clin Nutr. 1989 Nov;50(5 Suppl):1210-8; discussion 1231-5.

5. Chauncey HH, Muench ME, Kapur KK, Wayler AH. The effect of the loss of teeth on diet and nutrition. Int Dent J. 1984 Jun;34(2):98-104.

6. Chen AY, Frankowski R, Bishop-Leone J, Hebert T, Leyk S, Lewin J, Goepfert H. The development and validation of a dysphagia-specific quality-of-life questionnaire for patients with head and neck cancer: the M. D. Anderson dysphagia inventory. Arch Otolaryngol Head Neck Surg. 2001

7. Chow J, Hui E, Lee PK, Li W. Zygomatic implants--protocol for immediate occlusal loading: a preliminary report. J Oral Maxillofac Surg. 2006 May;64(5):804-11.

8. Chrcanovic BR, Albrektsson T, Wennerberg A. Survival and Complications of Zygomatic Implants: An Updated Systematic Review. J Oral Maxillofac Surg. 2016 Oct; $74(10): 1949-64$.

9. Davó R, Pons O. Prostheses supported by four immediately loaded zygomatic implants: a 3-year prospective study. Eur J Oral Implantol. 2013 Autumn;6(3):263-9.

10. Grisar K, Sinha D, Schoenaers J, Dormaar T, Politis C. Retrospective Analysis of Dental Implants Placed Between 2012 and 2014 : Indications, Risk Factors, and Early Survival. Int J Oral Maxillofac Implants. 2017 May/June;32(3):649-654.

11. Alva H, , Prasad DK, Prasad. Loading concepts in osseointegrated supported prosthesis- an Insight Guident,.Oct2012, Vol. 5 Issue 11, p16-20. 4p.

12. Hayter JP, Cawood JI. Oral rehabilitation with endosteal implants and free flaps. Int J Oral Maxillofac Surg. 1996 Feb;25(1):3-12.

13. Huber M. . Health: Definitions, The Netherlands, 2015 Louis Bolk Institute.

14. Kent G, Johns R. Effects of osseointegrated implants on psychological and social well-being: a comparison with replacement removable prostheses. Int J Oral Maxillofac Implants. 1994 Jan-Feb;9(1):103-6.

15. Laraway DC, Rogers SN. A structured review of journal articles reporting outcomes using the University of Washington Quality of Life Scale. Br J Oral Maxillofac Surg. 2012 Mar;50(2):122-31.

16. Moinpour CM, Feigl P, Metch B, Hayden KA, Meyskens FL Jr, Crowley J. Quality of life end points in cancer clinical trials: review and recommendations. J Natl Cancer Inst. 1989 Apr 5;81(7):485-95.

17. Mojon P, Rentsch A, Budtz-Jørgensen E. Relationship between prosthodontic status, caries, and periodontal disease in a geriatric population. Int J Prosthodont. 1995 Nov-Dec;8(6):564-71.

18. de Oliveira TR, Frigerio ML. Association between nutrition and the prosthetic condition in edentulous elderly. Gerodontology. 2004 Dec;21(4):205-8.

19. Pace-Balzan A, Cawood JI, Howell R, Lowe D, Rogers SN. The Liverpool Oral Rehabilitation Questionnaire: a pilot study. J Oral Rehabil. 2004 Jun;31(6):609-17.

20. Parel SM, Brånemark PI, Ohrnell LO, Svensson B. Remote implant anchorage for the rehabilitation of maxillary defects. J Prosthet Dent. 2001 Oct;86(4):377-81.

21. Rogers SN, McNally D, Mahmoud M, Chan MF, Humphris GM. Psychologic response of the edentulous patient after primary surgery for oral cancer: A cross-sectional study. J Prosthet Dent. 1999 Sep;82(3):317-21.

22. Sheiham A, Steele JG, Marcenes W, Finch S, Walls AW. The impact of oral health on stated ability to eat certain foods; findings from the National Diet and Nutrition Survey of Older People in Great Britain. Gerodontology. 1999 Jul;16(1):11-20.

23. Slade GD, Spencer AJ. Development and evaluation of the Oral Health Impact Profile. Community Dent Health. 1994 Mar;11(1):3-11.

24. Taylor RJ, Chepeha JC, Teknos TN, Bradford CR, Sharma PK, Terrell JE, Hogikyan ND, Wolf GT, Chepeha DB. Development and validation of the neck dissection impairment index: a quality of life measure. Arch Otolaryngol Head Neck Surg. 2002 Jan;128(1):44-9.

25. Trulsson U, Engstrand P, Berggren U, Nannmark U, Brånemark PI. Edentulousness and oral rehabilitation: experiences from the patients' perspective. Eur J Oral Sci. 2002 Dec;110(6):417-24.

26. Weymuller EA Jr, AlsarrafR, Yueh B, Deleyiannis FW, Coltrera MD. Analysis of the performance characteristics of the University of Washington Quality of Life instrument and its modification (UW-QOL-R). Arch Otolaryngol Head Neck Surg. 2001 May;127(5):489-93. 